\title{
Supervision, Condition Monitoring and Fault Diagnosis System in a Hybrid Renewable Energy Systems (HRES) Laboratory
}

\author{
E. Ariza ${ }^{1}$, A. Correcher ${ }^{2}$, C.Vargas ${ }^{1}$ and F. Morant ${ }^{2}$ \\ ${ }^{1}$ Instituto de Ingeniería Energética - IIE, Universitat Politècnica de València, \\ Camino de Vera Street, s/n, 46022, Valencia, (Spain) \\ email: helarcha@upv.es, carvarsa@upv.es \\ ${ }^{2}$ Instituto de Automática e Informática Industrial, Universitat Politècnica de València, \\ Camino de Vera Street, s/n, 46022, Valencia, (Spain). \\ email: ancorsal@upv.es, fmorant@isa.upv.es
}

\begin{abstract}
Hybrid renewable energy is a good alternative to get a reliable power supply; this idea allows local resources optimization, but, its ideal arrangement depends on available resources and final users' needs. To explore and evaluates possible solutions, the Institute for Energy Engineering of the Universitat Politècnica de València has assembled different renewable sources and energy storage in a laboratory of distributed renewable resources LabDER. This paper presents the progress in the supervisory system that includes condition monitoring and fault diagnosis.
\end{abstract}

\section{Key words}

Hybrid Renewable Energy Systems (HRES), Condition monitoring, Fault diagnosis.

\section{Introduction}

Each renewable power source have advantages over other power sources; however, the mix of power sources has more reliability to supply power to loads in grid connection or insulated mode; hybridization of renewable energy allows to take advantage of each source to minimize energy losses [1], [2], [3], [4], to increase net stability and to reduce energy storage [5], [6]. Many studies have been developed to find the ideal arrangement of Hybrid Renewable Energy Systems (HRES) [3], [7], [8], but possible solutions are related to available resources and final users; to explore and evaluate this different solutions, the Institute for Energy Engineering of the Universitat Politècnica de València has assembled different renewable sources and energy storage in a laboratory of distributed renewable resources (LabDER).

The structure of this work is: Section 2 shows a LabDER description, the Power sources, the available equipment in laboratory, the control system and the supervisor system. Section 3 shows more detailed the supervision system, its software, hardware and fault condition and fault detection procedures. Finally, section 4 presents some conclusions and future researches.

\section{General LabDER description}

LabDER has interconnected in a controlled micro grid: photovoltaic, wind, biomass, hydrogen fuel cell and storage energy (batteries and hydrogen), with a programmable load simulator. For a proper experiment management, LabDER includes two main systems; the Power Control System, that acts over a PLC and a hybrid inverter (grid-tied or insulated mode); in its turn, a hybrid Inverter sets up the operation modes of the micro grid: grid-tied, insulated, electrogenerator support, battery support, batteries charging, load supply, sell energy and renewable generation. Inverter can work in grid-tied mode, to inject energy from batteries or renewable resources; in insulated mode, the inverter creates an electrical network from a DC power source or follows an $\mathrm{AC}$ source as an another inverter or electrogenerator. The PLC controls a relays on-off to set up operation modes.

To monitor the energy flows, the control system gets information from inverter, PLC and a few power analyzers. Data is stored in a database and it is available in a virtual server.

The other main system has been developed to supervise the behavior of LabDER; it starts with data acquisition until condition monitoring and fault diagnosis.

\section{Supervision system}

This paper focuses on the supervision system. The goal is to acquire the data from each source to perform condition monitoring and fault diagnosis in LabDER. The first task was to develop a data acquisition system, with functions as: communication, decoding, storage, and data analysis. The second task is model development; starting from 
device modelling, then cluster modelling and finally integration of the clusters in a general model of LabDER. The third task is the condition monitoring and fault diagnosis, using mainly residual analysis and diagnosis algorithms. Principal elements as: hardware, software and condition monitoring and fault diagnosis, are described below:

\section{A. Hardware}

Data flow over a Modbus TCP/IP net, to achieve it, all data sources are transduced from their original protocol, to Modbus TCP/IP;

A computer is provided with two Ethernet cards; first one, drives the LAN and the second one, connects the PC to the university intranet and trough it to internet. That configuration creates a network where only circulates relevant data circulates, but it also allows remote supervision.

shows a basic scheme of the installation; the power line starts from the power source to inverter and finally to the micro grid. All systems have their protection, control systems and power analyzer. Communication path starts at the data source device (inverter, sensor, and power analyzer), it follows to a specific transducer (RS-232, RS485 or others to TCP/IP), it continues to the network switch and finally to a PC.

A computer is provided with two Ethernet cards; first one, drives the LAN and the second one, connects the PC to the university intranet and trough it to internet. That configuration creates a network where only circulates relevant data circulates, but it also allows remote supervision.

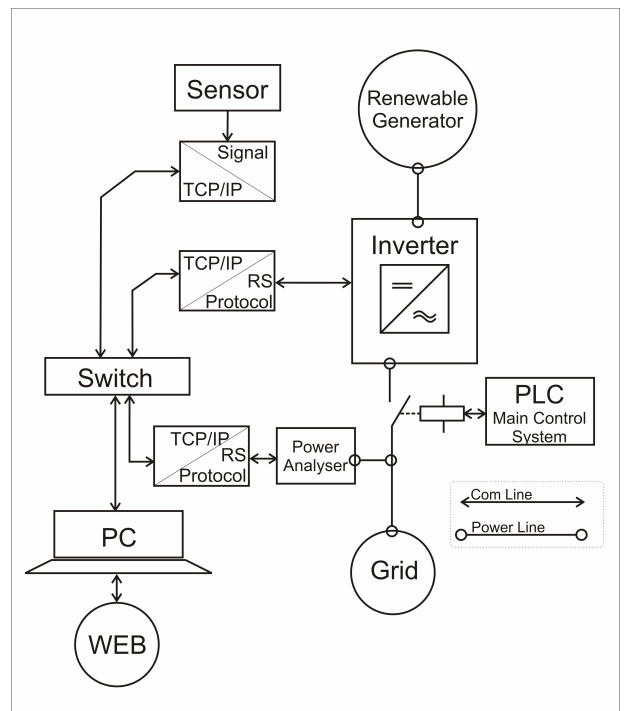

Fig. 1. Basic installation of a renewable generator

Table I presents a list of the equipment of LabDER in function and their origin protocols. To know LabDER energy consumption, a power analyzer has also been installed in the laboratory power input.

Table I. - List of communication equipment

\begin{tabular}{|c|l|c|}
\hline \multicolumn{1}{|c|}{ Cluster } & \multicolumn{1}{|c|}{ Device } & Protocol \\
\hline PV 2.125 kW & PV array & --- \\
\hline
\end{tabular}

\begin{tabular}{|l|l|l|}
\hline \multicolumn{1}{|c|}{ Cluster } & \multicolumn{1}{|c|}{ Device } & \multicolumn{1}{c|}{ Protocol } \\
\hline \multirow{4}{*}{ Wind Power $2.5 \mathrm{~kW}$} & Inverter & RS-232 \\
\cline { 2 - 3 } & G and T sensor & RS-485 \\
\hline \multirow{5}{*}{ Hydrogen 1.2 kW } & Wind turbine & --- \\
\cline { 2 - 3 } & Inverter & RS-485 \\
\cline { 2 - 3 } & Power analyzer & RS-485 \\
\cline { 2 - 3 } & anemometer & TPC/IP \\
\hline \multirow{5}{*}{ Biomass } & Electrolyzer & --- \\
\cline { 2 - 3 } & PEMFC & RS-232 \\
\cline { 2 - 3 } & PLC & TCP/IP \\
\cline { 2 - 3 } & Compressor & --- \\
\hline \multirow{5}{*}{ Grid Control } & Gasifier & --- \\
\cline { 2 - 3 } & Gas Analyzer & TCP/IP \\
\cline { 2 - 3 } & Gas engine generator & RS-485 \\
\cline { 2 - 3 } & Power Analyzer & --- \\
\hline Import Energy & PC control & TCP/IP \\
\cline { 2 - 3 } & Hybrid grid Inverter & --- \\
\cline { 2 - 3 } & PLC & --- \\
\cline { 2 - 3 } & Power bank & --- \\
\cline { 2 - 3 } & Power analyzers & TCP/IP \\
\hline & Power analyzers & RS-485 \\
\hline
\end{tabular}

In some clusters the communication function of several devices are concentrated in one single port; as hydrogen cluster case, wherein PLC concentrates the compressor and electrolyser data. The supervisor system only needs to communicate with the plc to get all data.

\section{B. Software}

All supervisory software are developed using a LabVIEW ${ }^{\circledR}$ environment and the program code is split following modules:

1) Supervisor: is a first user interface, in the screen is possible choose between experimental mode or supervisor mode; in the experimental mode, the user may configure the data recording frequency and select which clusters will be read during experiment. In the supervisor mode, all possible devices are read and recording data is fixed to one minute. The supervision system has a few screens to lets users on-line explore the system state.

2) Communications: this module is responsible to establish communication with data sources in a master-slave mode; the read registers Modbus command is transduced to any device protocol to obtain the memory register data. If communication is not available, this module will try to reconnect periodically. The registers are sent to global variables with their respective read time.

3) Save data: When communications are possible, this module records each device information in a general database.

4) Virtual Server: Each register is split into two numbers type integer and posted in a virtual server which acts as slave for another PC in the same net. This makes possible to share on-line information with the control system.

5) Server Reader: a similar module has been installed in the control system PC, creating a 
virtual server there. Server Reader module lets to obtain the control system data.

6) Supervisor Interface: Is a second user interface. In several screens is represented LabDER status as an SCADA without control role. In the first 7) screen shown in

8) , the user can watch: laboratory energy flows, active operation modes and basic values of sources and loads (energy, power, frequency, voltage, current and power factor).

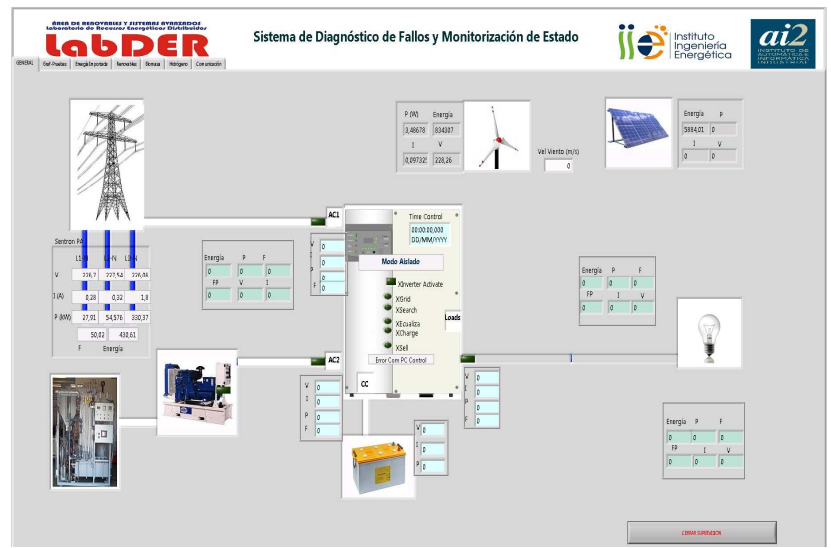

Fig. 2. Supervisor Interface Module, First screen.

The second screen shown in Fig. 3 displays historical graphs of power values, in the plot area can see renewable output power (PV and wind power); User can set the period and the output powers to be plotted; another similar screen lets to user check online system behavior; that is useful in experiment works.

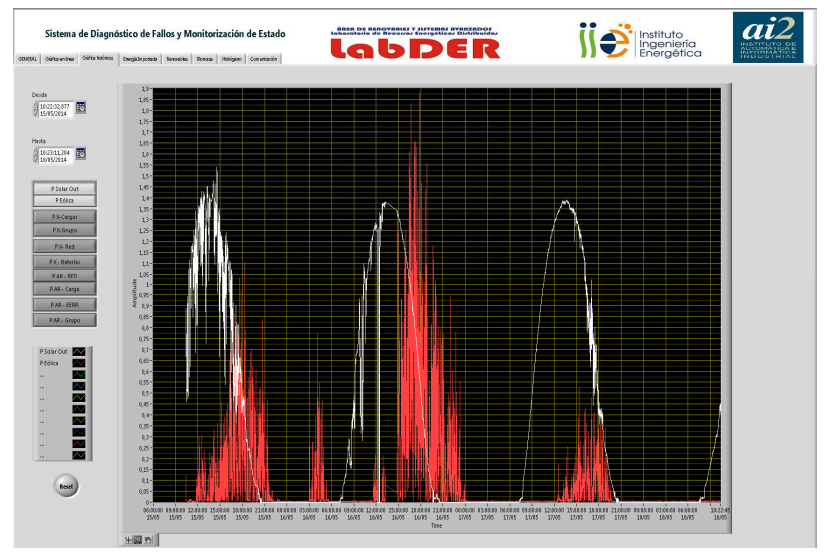

Fig. 3. Supervisor Interface Module, Second screen.

As it can be seen in Fig. 4, the third screen represents an extended PV and wind information. The user can view in detail the PV array production and inverter behavior. It also shows wind power production compared to a wind turbine manufacturer curve, and weather data as: solar radiation, external temperatures and wind speed.

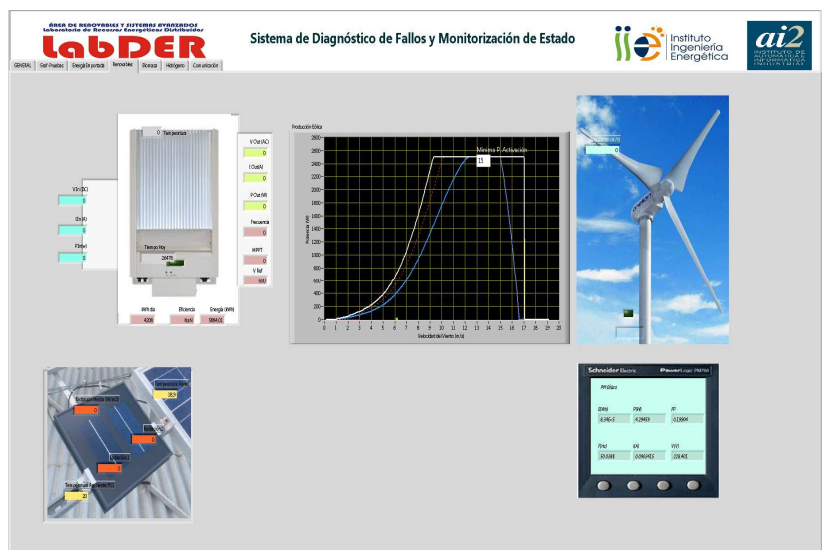

Fig. 4. Supervisor Interface Module, third screen.

Last screen is shown in Fig. 5. It represents the communication status and it allows the identification of any communication problem and it also solves it if possible, improving the information accuracy.

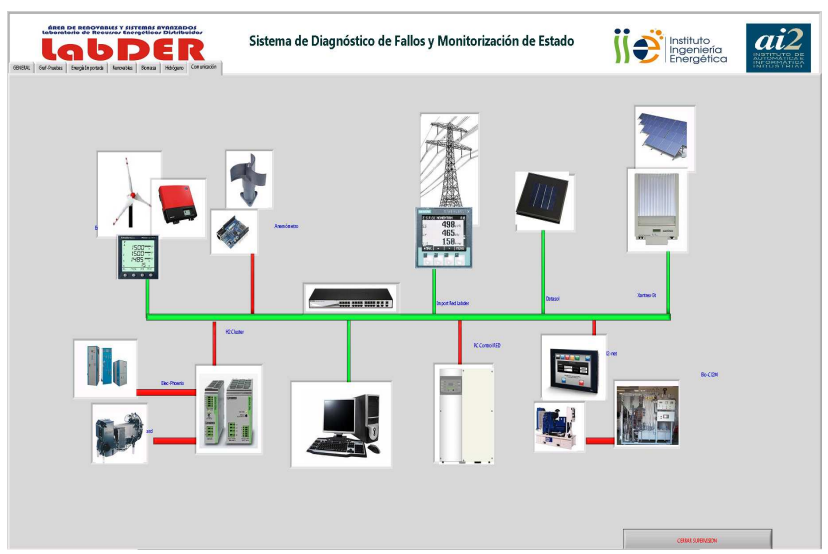

Fig. 5. Supervisor Interface Module, fourth screen.

9) Data Visor: is a user interface that queries the database and displays the data in graphic way; several filters as: date range, cluster device and variables; it allows the user to select the wanted information. The user also has tools to data processing as: $\mathrm{X}-\mathrm{Y}$ graphs, data synchronization, cursors by variable and display for values; information can be exported to spreadsheet or to clipboard as image. A print screen of this module is shown in Fig. 6.

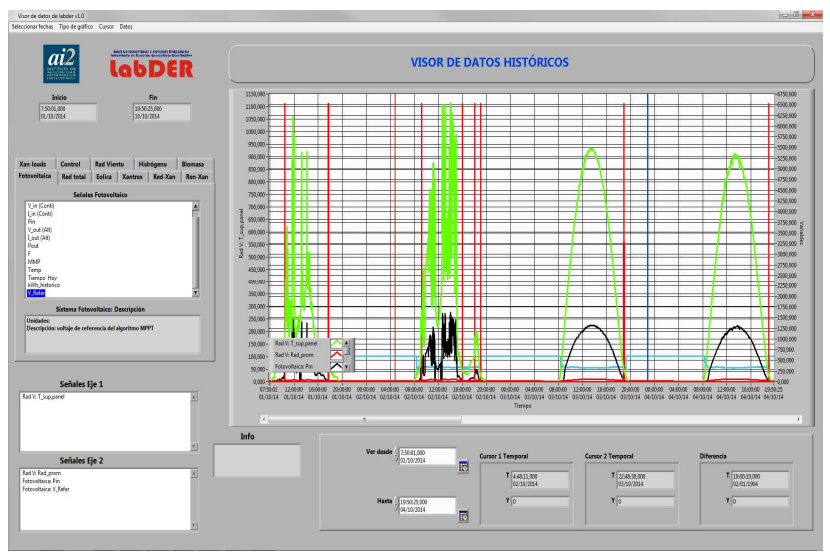

Fig. 6. Data Visor module 


\section{Condition Monitoring and fault diagnosis}

Each renewable energy source has different treatment for condition monitoring and fault diagnosis. The system works with two kinds of models. First, mathematical models are used when the equations that represent equipment performance are known. That includes the PV module or the PM fuel cell; second, heuristic models are considered when only input-output signals are available and there is not enough information available about inside device behaviour to build a mathematical model. After the implementation of each model, the following activities were carried out: simulation and calculation of standard deviations, model fitting, definition and development trend analysis and refinement of fault trees.

1. Mathematical Models. Several papers have worked over the development of mathematical models for renewable generation. In PV technology, most models start from circuit equivalent equations, using more or less parameters or complex equations creates more or less complex models ranging from single cell, modules and PV array including mismatch effect and inverters efficiency. LabDER model is based in [9] and [10]. PM fuel cell model are developed starting from [11],[12,][13] and [14].

2. Heuristic Models. The main scope of the heuristic treatment is to retrieve empirical information from experts and technical information from drawings and manuals for implementing a heuristic intelligent diagnosis based on symptoms using the most suitable technique for diagnosis of faults, having in count its operating status and variables involved. Table II presents the modelling techniques to simulate the behavior of devices in the cluster.

Table II. - Summary modeling treatment

\begin{tabular}{|c|c|c|}
\hline Cluster & Device & Model Description \\
\hline \multirow[t]{2}{*}{ PV } & PV Array & $\begin{array}{l}\text { Mathematical, from the } \\
\text { equivalent electrical circuit } \\
\text { equations, as a function of } \\
\text { irradiance and temperature. }\end{array}$ \\
\hline & Inverter & $\begin{array}{l}\text { Heuristic, from efficiency data } \\
\text { presented in the manufacturer's } \\
\text { data sheet }\end{array}$ \\
\hline \multirow[b]{2}{*}{$\begin{array}{l}\text { Wind } \\
\text { Power }\end{array}$} & Wind Turbine & $\begin{array}{l}\text { Heuristic, from power production } \\
\text { curve as a function of wind speed }\end{array}$ \\
\hline & Inverter & $\begin{array}{l}\text { Heuristic, from efficiency data } \\
\text { presented in the manufacturer's } \\
\text { data sheet. }\end{array}$ \\
\hline \multirow{3}{*}{ Hydrogen } & PMFC & $\begin{array}{l}\text { Mathematical, from Nerts's } \\
\text { equations. }\end{array}$ \\
\hline & Electrolyzer & $\begin{array}{l}\text { Mathematical, from Nerts's } \\
\text { equations. }\end{array}$ \\
\hline & Compressor & $\begin{array}{l}\text { Heuristic, from efficiency data } \\
\text { presented in the manufacturer's } \\
\text { data sheet. }\end{array}$ \\
\hline \multirow[b]{2}{*}{ Biomass } & Gasifier & Heuristic, from experimental data \\
\hline & $\begin{array}{l}\text { Gas } \\
\text { electrogenerator }\end{array}$ & $\begin{array}{l}\text { Heuristic, from efficiency data } \\
\text { presented in the manufacturer's } \\
\text { data sheet. }\end{array}$ \\
\hline Batteries & Batteries & $\begin{array}{l}\text { Mathematical, from Karden's } \\
\text { equivalent electrical circuit. }\end{array}$ \\
\hline
\end{tabular}

3. Condition Monitoring and fault diagnosis actions. After the device and cluster generation modelling process, the information obtained from models is compared with real data. Different variables of each model are compared with the real cluster readings to calculate its RMS; then a model parametric fitting is performed and therefore adjusted a cluster model is adjusted. New cluster model is simulated online and output data is permanently compared with real cluster performance to do online condition monitoring. When a compared variable has a residual value larger than the set value, that situation may consider a fault; from technical knowledge of equipment possible failures are identified and this information is loaded into identification and diagnosis algorithms.

LabVIEW ${ }^{\circledR}$ is used to develop algorithms based on fault trees rules and condition monitoring and for simulation, verification and implementation in the machine, leaving open the possibility for integration of analytic treatment.

\section{Conclusion}

LabDER is a very flexible renewable energy laboratory, allows experiment and evaluate different configurations of power generation mix. Supervisory system is a complex program which main features and tools are: data acquisition, data storage, system status representation, data mining, basic information analysis, condition monitoring, and fault diagnosis.

The fault diagnosis and the condition monitoring helps to improve the reliability of HRES, since this techniques provide accurate information to take decisions related to maintenance and repair of equipment and to choose an adequate generation mix.

\section{Acknowledgement}

This work has been supported by Universitat Politècnica de València within the project PAID-06-12, reference SP2012 0713.

\section{References}

[1] A. Afzal, M. Mohibullah, and V. Kumar Sharma, "Optimal hybrid renewable energy systems for energy security: a comparative study," Int. J. Sustain. Energy, vol. 29 , no. 1 , pp. $48-58$, Oct. 2009.

[2] B. Wichert, "PV-diesel hybrid energy systems for remote area power generation - A review of current practice and future developments," Renew. Sustain. Energy Rev., vol. 1, no. 3, pp. 209-228, Sep. 1997.

[3] O. Erdinc and M. Uzunoglu, "Optimum design of hybrid renewable energy systems: Overview of different approaches," Renew. Sustain. Energy Rev., vol. 16, no. 3, pp. 1412-1425, Abril 2012.

[4] E. Kasseris, Z. Samaras, and D. Zafeiris, "Optimization of a wind-power fuel-cell hybrid system in an autonomous 
electrical network environment," Renew. Energy, vol. 32, no. 1, pp. 57-79, Enero 2007.

[5] C. Chen, S. Duan, T. Cai, B. Liu, and G. Hu, "Optimal allocation and economic analysis of energy storage system in microgrids," Power Electron. IEEE Trans. On, vol. 26, no. 10, pp. 2762-2773, 2011.

[6] Eliza Peñalvo, "Optimization of Renewable Sources in a Hybrid Systems Operation," presented at the Electrical Engineering Electronic Journal EEEJ, Valencia, 2013, vol. 1.

[7] T. S. Ustun, C. Ozansoy, and A. Zayegh, "Recent developments in microgrids and example cases around the world-A review," Renew. Sustain. Energy Rev., vol. 15, no. 8, pp. 4030-4041, 2011.

[8] M. H. Nehrir, C. Wang, K. Strunz, H. Aki, R. Ramakumar, J. Bing, Z. Miao, and Z. Salameh, "A Review of Hybrid Renewable/Alternative Energy Systems for Electric Power Generation: Configurations, Control, and Applications," IEEE Trans. Sustain. Energy, vol. 2, no. 4, pp. 392-403, Oct. 2011.

[9] Y. Yadav, R. Roshan, S. Umashankar, D. Vijayakumar, and D. P. Kothari, "Real time simulation of solar photovoltaic module using labview data acquisition card," in 2013 International Conference on Energy Efficient Technologies for Sustainability (ICEETS), 2013, pp. 512-523.

[10] C.-H. Chang, J.-J. Zhu, and H.-L. Tsai, "Model-based performance diagnosis for PV systems," in Proceedings of SICE Annual Conference 2010, 2010, pp. 2139-2145.

[11] J. T. Pukrushpan, A. G. Stefanopoulou, and Huei Peng, "Modeling and control for PEM fuel cell stack system," presented at the Proceedings of the American Control Conference, Anchorage, AK, 2002, vol. 4, pp. 3117-3122.

[12] M. Y. El-Sharkh, A. Rahman, M. S. Alam, P. C. Byrne, A. A. Sakla, and T. Thomas, "A dynamic model for a standalone PEM fuel cell power plant for residential applications," J. Power Sources, vol. 138, no. 1-2, pp. 199204, Nov. 2004.

[13] Z. Zhang, X. Huang, J. Jiang, and B. Wu, "An improved dynamic model considering effects of temperature and equivalent internal resistance for PEM fuel cell power modules," J. Power Sources, vol. 161, no. 2, pp. 10621068, Oct. 2006.

[14] C. Wang, M. H. Nehrir, and S. R. Shaw, "Dynamic models and model validation for PEM fuel cells using electrical circuits," IEEE Trans. Energy Convers., vol. 20, no. 2, pp. 442-451, Jun. 2005. 